\title{
ALTERAÇÃO DA DURAÇÃO DO INTERVALO INTRAJORNADA NA REFORMA \\ TRABALHISTA À LUZ DOS PRINCÍPIOS DA VEDAÇÃO DO RETROCESSO SOCIAL E DA PROGRESSIVIDADE DA CONDIÇÃO SOCIAL DOS \\ TRABALHADORES
}

Daniel Rodney Weidman Junior ${ }^{1}$

Resumo: O estudo objetiva saber em que medida, diante dos princípios da vedação do retrocesso e da progressividade da condição social dos trabalhadores, as alterações legislativas implementadas pela Lei 13.467 de 2017, relativas ao intervalo intrajornada, são válidas e geram efeitos no campo jurídico.

Palavras-chave: Direito do Trabalho; Reforma Trabalhista; Duração do Intervalo Intrajornada; Princípio da Vedação do Retrocesso Social; Princípio da Progressividade da Condição Social dos Trabalhadores.

\section{BREAK DURATION IN THE BRAZILIAN LABOR REFORM ACCORDING TO THE PRINCIPLES OF NON-REGRESSION AND PROGRESSION OF WORKER'S SOCIAL CONDITION}

Abstract: The objective of this study is to check the constitucional validity of break duration rules proposed by the Brazilian labor reform in relation to the principles of non-regression and progression of worker's social condition.

Keywords: Labor Law; Labor Reform; Break Duration; Principle Of Non-Regression; Principle Of Progression Of Worker's Social Condition.

\footnotetext{
${ }^{1}$ Mestrando em Direito Humanos e Democracia pela Universidade Federal do Paraná - UFPR. Especialista em Direito do Trabalho pela Pontifícia Universidade Católica do Paraná - PUC/PR. Bacharel em Direito pela Universidade Federal do Paraná - UFPR. Servidor do Tribunal Regional do Trabalho da $9^{a}$ Região.
} 


\section{INTRODUÇÃO}

A Lei 13.467, de 13 de julho de 2017, levou a cabo a chamada "reforma trabalhista", sob a justificativa de "modernizar as relações de trabalho". Implementou diversas alterações na Consolidação das Leis do Trabalho - CLT (Decreto-Lei no 5.452, de $1^{\circ}$ de maio de 1943), muitas dessas de duvidosa compatibilidade com a Constituição Federal e com os princípios que regem o direito do trabalho.

Todas as mudanças e novidades trazidas, dentro de um claro contexto de favorecimento da atividade empresarial em detrimento da melhoria das condições sociais dos trabalhadores (art. $7^{\circ}$, caput, $\mathrm{CF}$ ), certamente provocarão grandes debates no âmbito da comunidade jurídica trabalhista, em especial nos Tribunais, que darão o tom de como a absorção ocorrerá na ordem jurídica.

Como bem demonstra Abili Lázaro Castro de Lima (2006), o atual panorama de dissipação dos direitos sociais tem relação, entre outros fatores, com o fenômeno da globalização. Ela pode ser entendida "como uma crescente interconexão em vários níveis da vida cotidiana a diversos lugares longínquos no mundo" e, dentre as suas várias dimensões, como a política, a social, a ambiental e a cultural, destaca-se a econômica, que atua como "o fio condutor" das demais (2006, p. 39).

A globalização econômica é operacionalizada pelo chamado "neoliberalismo", política econômica que defende o Estado Mínimo e o livre mercado e que tem como um de seus pressupostos a redução da proteção estatal no campo social (LIMA, 2006, p. 41).

A internacionalização do comércio, a mobilidade do capital e o agigantamento do volume de sua circulação por todo o mundo tem contribuído para a mitigação do poder dos Estados, os quais perderam espaço para as empresas transnacionais. Estas já há muito tempo detêm poder econômico superior ao de muitos Estados e influenciam diretamente em suas políticas econômicas. Em consonância com a percepção do enfraquecimento estatal, Javier Tajadura Tejada expõe que

La ruptura del nexo fundamental Estado-nación-mercado, esto es, de la simetría entre el espacio político configurado por el Estado nacional y el espacio económico determinado por el mercado global, ha provocado una pérdida notable de la soberanía de los Estados en la determinación de sus políticas económicas. (2006, p. 127).

Especificamente no que se refere às relações laborais, verifica-se uma divisão internacional do trabalho, resultante da confluência do capital para localidades nas quais os salários são mais baixos, o que leva a uma concorrência entre trabalhadores de diferentes países. 


\title{
ALTERAÇÃO DA DURAÇÃO DO INTERVALO INTRAJORNADA NA REFORMA TRABALHISTA À LUZ DOS PRINCÍPIOS DA VEDAÇÃO DO RETROCESSO SOCIAL E DA PROGRESSIVIDADE DA CONDIÇÃO SOCIAL DOS TRABALHADORES
}

As fronteiras dos Estados tornam-se, nesse aspecto, incapazes de proteger os mercados de trabalho internos.

Nesse contexto, os Estados vêm perdendo a capacidade de salvaguardar os direitos sociais, nos quais se incluem os direitos trabalhistas. Daniel Sarmento afirma que o Estado, sob o impacto da globalização, debilita-se,

\begin{abstract}
na medida em que vai perdendo o domínio sobre as variáveis que influem na sua economia. Deteriora-se a sua capacidade de formulação e implementação de políticas públicas, de regulamentação e fiscalização do seu mercado interno, e com isso o seu poder de garantir a eficácia dos direitos sociais (2001, p. 154).
\end{abstract}

Ao constatar a dificuldade de operacionalizar e garantir os direitos fundamentais no âmbito laboral, Aldacy Rachid Coutinho afirma que

exatamente nas mais recentes tentativas de influxo é que o primado das liberdades públicas (...) de um Estado não intervencionista são apontadas como a condição da "modernização" das relações de trabalho, fruto dos embates ideológicos travados com as ideias neoliberais de supremacia do negociado sobre o legislado, desregulamentação e flexibilização (2014, p. 89).

Como não poderia deixar de ser, tendo em vista os efeitos econômicos globalizantes, a propalada necessidade de "reformas", de que tanto se tem falado no Brasil, e a sua efetiva implementação, igualmente encontram equivalência em outras comunidades. Abordando a experiência da União Europeia, o Professor português António José Avelãs Nunes assevera que, sob o discurso de possibilitar "mercados de trabalho que reajam rapidamente às mudanças econômicas" e que permitam "manter a capacidade concorrencial da economia da "União", tem-se realizado "reformas estruturais", qualificadas como "inevitáveis, quase naturais e indispensáveis para a salvação do mundo" (2016, p. 133). E os resultados são perturbadores. Ressaltam-se, dentre os citados por esse professor a precarização no emprego, a maior facilidade de despedir, o aumento das horas de trabalho, a redução do poder de compra dos salários, a concessão de mais facilidades aos patrões quanto à mobilidade de horários e de locais de trabalhos, a baixa dos níveis de proteção social e o agravamento das desigualdades sociais (2016, p. 133).

O já citado jurista espanhol Javier Tajadura Tejadas identifica, da mesma forma, resultados dessa onda globalizante, tais como perda de controle da política monetária, crise do sistema fiscal, privatização do setor público da economia e, saliente-se, por serem mais diretamente relacionadas às reflexões aqui realizadas, embora não devam deixar de ser entendidas em conjunto com os demais, a flexibilidade e a precariedade do trabalho (2006, p. 127). 
As reformas implementadas mundialmente contribuem para a elevação da desigualdade social e para a crescente concentração de renda. É o que se verificou na Espanha, país que no início da década passou por reforma trabalhista de semelhante índole. Segundo notícia publicada no "el Periódico de Aragón” em 16 de janeiro de 2017 (SALA, 2017), a precariedade das condições de trabalho e a desvalorização salarial promovida pela reforma laboral elevou a proporção de trabalhadores pobres para a terceira mais alta da União Europeia, atrás apenas da Romênia e da Grécia. Enquanto a renda média naquele país caiu 9\% entre 2007 e 2014, a queda da renda dos 10\% mais pobres foi mais que o dobro: $21 \%$. De se destacar, igualmente, que enquanto em 2007 os $10 \%$ mais ricos tinham uma renda 10 vezes superior àquela dos 10\% mais pobres, em 2015 essa diferença saltou para 15 vezes. Não se trata de acontecimento isolado. De acordo com estudo da organização não-governamental britânica Oxfam, no ano de 2015 pela primeira vez a riqueza acumulada pela parcela $1 \%$ mais rica da população passou a equivaler à riqueza da parcela relativa aos 99\% restantes (OXFAM, 2017).

Embora, na esteira do que anotou Pedro de Veja García, o diagnóstico seja de que na tensão entre a lógica das valorações políticas, que legitima e justifica a ação estatal, e a lógica do cálculo e da ganância que orienta as ações do mercado cosmopolita, o desmoronamento da razão política venha propiciando à razão econômica o comando da história (1998, p. 13), a proteção e efetiva eficácia dos Direitos Sociais em face das ameaças que provêm das forças econômicas passa por uma reversão de trajetória, com o fortalecimento da democracia e de suas instituições, destinadas a fazer prevalecer os interesses dos cidadãos.

As Constituições desempenham papel fundamental nesse caminho. Na famosa obra “A Força Normativa da Constituição”, Konrad Hesse construiu fundamentação para afastar o entendimento de que a Constituição seria uma simples folha de papel, reflexo dos fatores reais de poder (nos termos da terminologia de Ferdinand Lassalle). Para o famoso jurista, a Constituição tem "pretensão de eficácia" e "procura imprimir ordem e conformação à realidade política e social". Além de ser determinada pela realidade social, é, simultaneamente, determinante em relação a ela (1991, p. 15).

Considerando que as forças econômicas efetivamente influenciam na forma de constituição e de regulação das relações sociais, é necessária a existência de um Estado politicamente fortalecido, capaz de garantir a normatividade oriunda de sua Constituição.

Ao constitucionalismo cumpre, como bem assevera Felipe Derbli, "resistir aos avanços da economia globalizada e às novas formas de exclusão social que lhe são correlatas, 


\section{ALTERAÇÃO DA DURAÇÃO DO INTERVALO INTRAJORNADA NA REFORMA TRABALHISTA À LUZ DOS PRINCÍPIOS DA VEDAÇÃO DO RETROCESSO SOCIAL E DA PROGRESSIVIDADE DA CONDIÇÃO SOCIAL DOS TRABALHADORES}

tanto quanto possível e necessário para a realização de seus objetivos de democracia pluralista e justiça social" (2007, p. 41).

No desenvolvimento dos acontecimentos históricos, especialmente em momentos de crise, a Constituição muitas vezes torna-se a última barreira para a defesa dos direitos sociais. O Poder Judiciário ganha relevo por ser, ordinariamente, a palavra final quanto à interpretação e aplicação das normas constitucionais, inclusive em face da atuação do Poder Legislativo na sua função típica.

Exerce importante papel na defesa dos direitos fundamentais sociais a teorização sobre a vedação do retrocesso, que prescreve a inconstitucionalidade da eliminação de direitos dessa natureza já concretizados por normas infraconstitucionais.

É clara a conexão do panorama de dissipação dos direitos sociais com a reforma trabalhista implementada em 2017. Um dos principais eixos desta foi o estabelecimento de normas visando a prevalência do negociado sobre o legislado, com a aprovação de textos normativos como o dos artigos $8^{\circ}, \S 3^{\circ}, 611$-A e 611-B da CLT.

No que se refere ao intervalo intrajornada, objeto deste trabalho, a CLT passou a conter no artigo 611-A, III, incluído pela Lei 13.467/2017, disposição permitindo redução de sua duração:

\footnotetext{
Art. 611-A. A convenção coletiva e o acordo coletivo de trabalho têm prevalência sobre a lei quando, entre outros, dispuserem sobre:

(...)

III - intervalo intrajornada, respeitado o limite mínimo de trinta minutos para jornadas superiores a seis horas;

$\cdots$
}

Apesar de no artigo 611-B, XVII, também incluído na CLT pela reforma, constar como objeto ilícito da negociação coletiva a supressão ou redução de "normas de saúde, higiene e segurança do trabalho previstas em lei ou em normas regulamentadoras do Ministério do Trabalho", em inicial paralelismo com a proteção ao direito social fundamental estabelecida no artigo $7^{\circ}$, XXII, da Constituição Federal, que estabelece ser direito fundamental dos trabalhadores urbanos e rurais a "redução dos riscos inerentes ao trabalho, por meio de normas de saúde, higiene e segurança”, acabou por inserir no parágrafo único do mesmo artigo previsão de que as regras sobre duração do trabalho e intervalos não são consideradas como normas de saúde, higiene e segurança para fins de afastar supressão ou redução de direitos por meio de negociação coletiva.

Dessa forma, partindo-se da hipótese de que o artigo 71, caput e parágrafos $1^{\circ}$ e $3^{\circ}$, da CLT, em suas redações originais, não alteradas, contém o regramento geral quanto à duração 
do intervalo intrajornada e, dentre tantas outras normas regulamentadoras de natureza de saúde, higiene e segurança do trabalho, densificam o direito social fundamental previsto no artigo $7^{\circ}$, XXII, da Constituição Federal, coloca-se o problema de pesquisa de saber em que medida, diante dos princípios da vedação do retrocesso e da progressividade da condição social dos trabalhadores, as alterações legislativas mencionadas são válidas e geram efeitos no campo jurídico.

Considerando tal problema, os objetivos deste artigo serão: compreender e analisar o princípio da vedação do retrocesso social; identificar e analisar as normas da CLT sobre a duração do intervalo intrajornada; relacionar tais normas com o direito fundamental de "redução dos riscos inerentes ao trabalho, por meio de normas de saúde, higiene e segurança" (artigo $7^{\circ}$, XXII, da CF); relacionar o direito ao intervalo intrajornada com os princípios da vedação do retrocesso e da progressão da condição social dos trabalhadores; verificar a validade da redução do intervalo intrajornada por meio de negociação coletiva; e, admitindo-se a validade, identificar limites impostos pelo mencionados princípios e direito social fundamental.

A abordagem do problema de pesquisa será desenvolvida com base em pesquisa bibliográfica da doutrina constitucional e trabalhista e da jurisprudência relacionada ao tema.

\section{O PRINCÍPIO DA VEDAÇÃO DO RETROCESSO}

Tem-se entendido que o princípio da vedação do retrocesso proíbe, sob pena de inconstitucionalidade, que a densificação de um direito fundamental realizada por meio de lei seja elidida por lei posterior que esvazie seu conteúdo ou sua eficácia.

Nesse tema é bastante difundida a lição de Luís Roberto Barroso no sentido de que, por esse princípio, "se uma lei, ao regulamentar um mandamento constitucional, instituir determinado direito, ele se incorpora ao patrimônio jurídico da cidadania e não pode ser absolutamente suprimido" (2002, p. 158).

Para Felipe Derbli, "haverá retrocesso social quando o legislador, comissiva e arbitrariamente, retornar a um estado correlato a uma primitiva omissão constitucional ou reduzir o grau de concretização de uma norma definidora de direito social” (2007, p. 240). Sustenta o autor que, uma vez cumprindo o legislador a obrigação estabelecida pela Constituição de editar leis concretizadoras dos direitos fundamentais sociais, conclui-se, de 


\title{
ALTERAÇÃO DA DURAÇÃO DO INTERVALO INTRAJORNADA NA REFORMA TRABALHISTA À LUZ DOS PRINCÍPIOS DA VEDAÇÃO DO RETROCESSO SOCIAL E DA PROGRESSIVIDADE DA CONDIÇÃO SOCIAL DOS TRABALHADORES
}

forma lógica, não ser possível revogá-las sem a substituição por outra regulamentação ou reduzir, de forma arbitrária ou desproporcional, o patamar conquistado (2008, p. 344).

Não há unanimidade na doutrina quanto à amplitude do princípio da vedação do retrocesso. Segundo Felipe Derbli, conforme já era possível intuir do conceito por ele formulado sobre o princípio, acima citado, restringe-se apenas aos direitos sociais (2008, p. 372-373). Todavia entendemos mais adequado a posição sustentada por autores como Ingo Wolfgang Sarlet (2015, p. 469), Luís Roberto Barroso e Ana Paula de Barcellos (BARROSO; BARCELLOS, 2003, p. 170) e Paulo Ricardo Schier e Adriana da Costa Ricardo Schier (SCHIER, P; SCHIER, A, 2016, p. 210-211), os quais consideram aplicáveis a todos os direitos fundamentais. Tal aspecto não será objeto de maiores detalhamentos aqui em razão dessa divergência não colocar em dúvida a incidência do princípio em relação aos direitos trabalhistas, abarcados pelos direitos sociais.

A vedação do retrocesso não é prevista expressamente pelo direito positivo. Constituise como um princípio implícito, decorrente do sistema constitucional.

Elementos implícitos são, de forma geral, naturais à linguagem, não sendo exclusividade do texto jurídico-normativo. É razoável se concluir que, na elaboração dos textos normativos, não se tenha conseguido explicitar toda a complexidade do substrato histórico que convergiu para a definição dos princípios e regras positivados e que, por meio destes, pretendeuse expressar. Há todo um conjunto de informações preexistentes e presumidas que influenciam na interpretação que se faz das normas (BARBOSA, 2014, p. 154-155). Como observa Estefânia Maria de Queiroz Barboza, se tanto a Constituição quanto outras leis escritas são

\begin{abstract}
uma tentativa de comunicar as normas jurídicas, então seu significado é influenciado pelos princípios de comunicação linguística, entre os quais o que determina que em nenhuma comunidade seu conteúdo está totalmente expresso nas palavras utilizadas para demonstrá-lo (2014, p. 155).
\end{abstract}

A existência de princípios implícitos é admitida pela própria Constituição Federal ao prever em seu artigo $5^{\circ}, \S 2^{\circ}$, que os direitos e garantias nela expressos "não excluem outros decorrentes do regime e dos princípios por ela adotados"2.

Embora não escritos, os princípios constitucionais implícitos têm o mesmo efeito jurígeno que os princípios constitucionais expressos de invalidar a legislação ordinária

\footnotetext{
${ }^{2}$ Conforme afirma Paulo Ricardo Schier, esse dispositivo significaria muito pouco se apenas pretendesse admitir a existência de princípios fundamentais implícitos, uma vez que para a constatação destes seria suficiente a atividade hermenêutica. Para ele o dispositivo estabelece uma cláusula de abertura dos direitos fundamentais, de forma a abranger, além de valores expressos e implícitos dentro do catálogo do Título II da Constituição, igualmente valores expressos e implícitos fora dele (SCHIER, P., 2005, p. 158).
} 
incompatível, desvelando-se sua importância no controle de constitucionalidade (SCHIER, P., 2005, p. 157).

Ingo Wolfgang Sarlet apresenta argumentos que fundamentam a concepção do princípio da vedação do retrocesso como um princípio implícito (2015, p. 464-466).

Aponta, inicialmente, a sua derivação do princípio do Estado democrático e social de Direito e da ligação deste último com os princípios da segurança jurídica e da proteção da confiança, os quais permitem estabilidade das relações jurídicas e da própria ordem jurídica como tal (2015, p. 451-452 e 464-465). No pensamento constitucional contemporâneo consolidou-se a ideia de que um Estado de Direito é também um Estado de segurança jurídica, pois do contrário eventual maioria parlamentar poderia submeter a comunidade a leis abusivas. Tem-se considerado, assim, a segurança jurídica como

\begin{abstract}
subprincípio concretizador do princípio fundamental e estruturante do Estado de Direito. Assim, para além de assumir a condição de direito fundamental da pessoa humana, a segurança jurídica constitui simultaneamente princípio fundamental da ordem jurídica estatal... (SARLET, 200?, p. 4-5).
\end{abstract}

É de se ressaltar que o Supremo Tribunal Federal já se manifestou considerando o princípio da segurança jurídica como sendo subprincípio do Estado de Direito e tendo, como elemento, o princípio da confiança ${ }^{3}$.

O valor segurança é acolhido pela constituição brasileira, a qual o menciona, de forma ampla, no Preâmbulo e no caput de seu artigo $5^{\circ}$, como bem jurídico a ser assegurado. Encontrase homenageado em diversos dispositivos fulcrais, a exemplo dos princípios da legalidade (artigo. $5^{\circ}$, II, da CF), do devido processo legal (artigo. $5^{\circ}$, LIV, da CF), da anterioridade da lei penal (artigo $5^{\circ}$, XXXIX, da CF) e da irretroatividade tributária (artigo. 150, III, “a”, da CF).

Dentro das dimensões do princípio da segurança, insere-se, de forma mais específica e dirigida ao tema aqui abordado, a proteção em face de medidas retrocessivas. Estas medidas, apesar de relacionadas à proteção contra atos de cunho retroativo - de certa forma já albergados pelo direito positivo, a exemplo da previsão de preservação do direito adquirido, do ato jurídico perfeito e da coisa julgada (artigo $5^{\circ}, \mathrm{XXXVI,} \mathrm{da} \mathrm{CF)} \mathrm{-} \mathrm{assim} \mathrm{como} \mathrm{contra} \mathrm{atos} \mathrm{que} \mathrm{visem}$ alterar determinados conteúdos da Constituição pelo poder constituinte reformador - hipótese das cláusulas pétreas, limites materiais à reforma constitucional (artigo 60, § 4 , da $\mathrm{CF}$ ) -, demandam, também, proteção contra medidas de efeitos prospectivos (SARLET, 2015, p. 453-

\footnotetext{
${ }^{3}$ É o que se verifica nos julgamentos realizados nos Mandados de Segurança 22357/DF (Relator: Ministro Gilmar Mendes. Julgamento em 27/05/2004) e 24268/MG (Relatora Ministra Ellen Gracie. Julgamento em 05/02/2004).
} 


\title{
ALTERAÇÃO DA DURAÇÃO DO INTERVALO INTRAJORNADA NA REFORMA TRABALHISTA À LUZ DOS PRINCÍPIOS DA VEDAÇÃO DO RETROCESSO SOCIAL E DA PROGRESSIVIDADE DA CONDIÇÃO SOCIAL DOS TRABALHADORES
}

454 e 465). É exatamente aqui que se insere a proteção contra atos que pretendam eliminar a concretização de direitos sociais efetuada por lei. A segurança jurídica é uma chave de grande importância no atual momento de crise. Segundo Ingo Wolfgang Sarlet (2005, p. 7),

\begin{abstract}
justamente em face da instabilidade institucional, social e econômica vivenciada (...), que inevitavelmente tem resultado numa maratona reformista, igualmente acompanhada por elevados níveis de instabilidade, verifica-se que o reconhecimento, a eficácia e a efetividade do direito à segurança cada vez mais assume papel de destaque na constelação dos princípios e direitos fundamentais.
\end{abstract}

Referido jurista também aponta a derivação do princípio implícito da vedação do retrocesso do princípio da dignidade da pessoa humana, fundamento da República Federativa do Brasil (artigo 1º III, da CF). Nas suas palavras, este princípio, “exigindo a satisfação - por meio de prestações positivas (e, portanto, de direitos fundamentais sociais) - de uma existência condigna para todos, tem como efeito, na sua perspectiva negativa, a inviabilidade de medidas que fique aquém deste patamar" (SARLET, 2015, p. 464).

A decorrência igualmente é extraída do princípio da máxima eficácia e efetividade das normas definidoras de direitos fundamentais (artigo $5^{\circ}, \S 1^{\circ}$, da CF) (SARLET, 2015, p. 464). A previsão de aplicação imediata das normas definidoras dos direitos e garantias fundamentais implica a geração de efeitos jurídicos independentemente de edição de normas regulamentadoras, submetendo desde sua vigência os três poderes da república. Como bem salienta Daniel Wunder Hachem “a previsão surge como forma de superar a ideia de que os direitos fundamentais só ganham operatividade após serem enunciados pelo legislador ordinário, intelecção própria da racionalidade vigente na Europa continental do século XIX ...” (2013, p. 206). Tal princípio não afasta a exigência, contudo, de algum nível de regulamentação dos direitos fundamentais para que estes sejam adequadamente efetivados. Considerando caber ao operador jurídico maximizar a eficácia e aplicação das normas fundamentais, se estas se encontrarem densificadas, originando direitos subjetivos aos cidadãos, qualquer legislação ordinária que simplesmente revogue a legislação regulamentar deve ser considerada inconstitucional. Nesse sentido, argui Luís Roberto Barroso que

\begin{abstract}
o que se veda é o ataque à efetividade da norma, que foi alcançada a partir de sua regulamentação. Assim, por exemplo, se o legislador infraconstitucional deu concretude a uma norma programática ou tornou viável o exercício de um direito que dependia de sua intermediação, não poderá simplesmente revogar o ato legislativo... (2002, p. 158-159).
\end{abstract}

Necessário afirmar, a essa altura, que não se está a defender que o princípio da vedação do retrocesso estabeleça uma proibição absoluta de alteração da legislação infraconstitucional que regulamenta os direitos fundamentais. Esse debate ganha ainda maior relevância em face 
dos direitos sociais, especificamente em sua dimensão principal, que exige do Estado deveres de promoção dependentes da existência de recursos ${ }^{4}$.

É bom deixar claro que o condicionamento financeiro não é exclusividade dos direitos sociais, tendo relação com todos os direitos fundamentais, nos quais se incluem os direitos de liberdade, classicamente considerados como direitos negativos. Como bem ressalta Jorge Reis Novais, os direitos de liberdade não teriam grande efetividade sem as prestações estatais positivas destinadas a garantí-los institucionalmente, prestações essas que exigem enorme quantidade de verbas públicas (2010, p. 94) ${ }^{5}$. O fato dos custos vultosos com esses direitos "serem vistos como "naturais", inerentes à própria existência do Estado de Direito, é que leva a não contabilizá-los, a mantê-los ocultos, ao contrário do que se tende, em contrapartida, a fazer salientar relativamente aos muito mais controvertidos diretos sociais" (NOVAIS, 2010, p. 95).

Não se pode ignorar, dentro de um contexto de escassez moderada ${ }^{6}$, a primazia dos poderes legislativo e executivo em selecionar prioridades, definir políticas públicas e gerir recursos públicos. Isso abrange, inclusive, a possibilidade de priorização de algumas prestações sociais em face de outras, com o consequente deslocamento de meios estatais e recursos financeiros de uma área para outra. Entender de forma contrária geraria um engessamento inaceitável da atuação da esfera política. Nesse aspecto, expõe Ingo Wolfgang Sarlet (2015, p. 467) que uma proibição absoluta

não apenas implica a afetação substancial da necessária possibilidade de revisão que é peculiar à função legislativa, mas também desconsidera a indispensável possibilidade (e necessidade) de reavaliação global e permanente das metas da ação estatal e do próprio desempenho na consecução de tais metas...

\footnotetext{
${ }^{4}$ Os direitos fundamentais devem ser vistos como um todo, de modo que de cada direito fundamental se possa extrair ao mesmo tempo deveres estatais de respeitar, de proteger e de promover (NOVAIS, 2010, p. 97). O dever de respeitar está conectado com a abstenção de intervir por parte do Estado, associada normalmente aos direitos de liberdade. O dever de proteger, por sua vez, está relacionado à proteção estatal em face de ações de terceiros. Por fim, o dever de promoção implica prestações por parte do Estado, função que normalmente prepondera nos direitos sociais, mas não são sua única expressão. É o que se observa, direcionando-se ao objeto deste artigo, em relação ao direito fundamental social de "redução dos riscos inerentes ao trabalho, por meio de normas de saúde, higiene e segurança", expresso no artigo $7^{\circ}, \mathrm{XXII}$, da CF, em face do ressaltam-se ações protetivas.

${ }^{5} \mathrm{Na}$ mesma página encontra-se a seguinte exemplificação: “... bastaria considerar o que ocorre com esse direito negativo tradicional que é o direito de propriedade. Sem o poderoso arsenal de normas, instituições, funcionários, protecção policial ou aparelho e intervenção judiciais destinados a garantir, preventiva ou repressivamente, a efectividade do direito à propriedade privada, o direito negativo seria incapaz de desenvolver quaisquer efeitos práticos".

${ }^{6}$ Jorge Reis Novais afirma que nas situações típicas de Estado Social a escassez não é absoluta, mas sim moderada, pois, na prática, sempre há algum dinheiro para a efetivação de direitos sociais. Simultaneamente, contudo, há várias possibilidades de escolha do destino dos recursos disponíveis (NOVAIS, 2010, p. 91).
}

Rev. de Direito do Trabalho e Meio Ambiente do Trabalho | e-ISSN: 2525-9857 | Porto Alegre | v. 4 | n. 2 | p. 135 - 155 |

Jul/Dez. 2018 


\section{ALTERAÇÃO DA DURAÇÃO DO INTERVALO INTRAJORNADA NA REFORMA TRABALHISTA À LUZ DOS PRINCÍPIOS DA VEDAÇÃO DO RETROCESSO SOCIAL E DA PROGRESSIVIDADE DA \\ CONDIÇÃO SOCIAL DOS TRABALHADORES}

A implementação progressiva dos direitos sociais, ideia promovida internacionalmente $^{7}$, não deve, portanto, ser aceita e analisada sob um ponto de vista compartimentalizado. Por outro lado, também não se pode dar razão aos que defendem uma liberdade total de conformação ao legislador, com autonomia para voltar atrás nas suas decisões, sob o entendimento de que o conteúdo dos direitos fundamentais é indeterminável sem sua regulamentação (SARLET, 200?, p. 21), pois estar-se-ia conferindo ao parlamento poder de disposição de conteúdo essencial de direitos fundamentais.

Por ter natureza de princípio, a vedação do retrocesso encerra apenas uma proteção relativa. De acordo com a teoria de Robert Alexy (2014, p. 90), princípios são mandamentos de otimização, "são normas que ordenam que algo seja realizado na maior medida possível dentro das possibilidades jurídicas e fáticas existentes”. Podem, portanto, ser satisfeitos em graus variados (2014, p. 90). Diferentemente, as regras ou são satisfeitas ou não satisfeitas (2014, p. 91). Em um conflito de regras, a solução ocorre no campo da validade. Quando não há uma cláusula de exceção que elimine o conflito, uma das regras deve ser considerada inválida. A colisão de princípios, por sua vez, ocorre no campo do peso. Um dos princípios conflitantes deverá prevalecer, sob determinadas condições, sem invalidar o outro (2014, p. 92-94).

No caso concreto, portanto, caberá a realização de sopesamento. Mas o núcleo essencial do princípio da vedação retrocesso, em qualquer caso, deve ser preservado. Esse núcleo consiste, conforme ensinamento de Paulo Ricardo Schier e Adriana da Costa Ricardo Schier

na proibição dirigida ao legislador ordinário de revogar normas cujos conteúdos tenham condensado direitos fundamentais. Para incidir tal proteção, é necessário que esses conteúdos gozem de uma aceitação geral e ainda estejam referidos ao núcleo essencial dos direitos regulamentados (2016, p. 213).

O legislador está, portanto, vinculado ao núcleo essencial do direito fundamental concretizado que desfrute de um consenso geral.

O consenso geral deve ser observado, segundo os autores citados, "em relação à relevância do conteúdo trazido pela legislação infraconstitucional, como requisito que garanta a máxima efetividade do direito regulado" (2016, p. 2013).

\footnotetext{
${ }^{7}$ O Decreto $\mathrm{n}^{\text {o }}$ 591, de 6 de julho de 1992 aceitou na ordem interna brasileira o pacto internacional sobre direitos econômicos, sociais e culturais. O documento internacional prevê em seu artigo $2^{\circ}$, item 1, que "Cada Estado Parte do presente Pacto compromete-se a adotar medidas, tanto por esforço próprio como pela assistência e cooperação internacionais, principalmente nos planos econômico e técnico, até o máximo de seus recursos disponíveis, que visem a assegurar, progressivamente, por todos os meios apropriados, o pleno exercício dos direitos reconhecidos no presente Pacto, incluindo, em particular, a adoção de medidas legislativas".
} 
O núcleo essencial dos direitos fundamentais, em geral, está intimamente ligado ao princípio da dignidade humana e, especialmente quanto aos direitos sociais prestacionais, às prestações materiais indispensáveis a uma vida com dignidade (SARLET, 2015, p. 471).

A teorização sobre o princípio da vedação do retrocesso aqui apresentada será utilizada, no próximo tópico, para analisar a validade das alterações realizadas pela reforma trabalhista em relação à duração do intervalo intrajornada.

\section{TEMPO DESTINADO AO INTERVALO INTRAJORNADA - VALIDADE DAS ALTERAÇÕES PROMOVIDAS NA LEI 13.467, DE 13 DE JULHO DE 2017}

Os tempos destinados à jornada de trabalho e aos intervalos não são um problema que deve ser analisado sob um ponto de vista estritamente econômico (DELGADO, 2008, p. 921). Têm relação direta com a saúde e a segurança no trabalho e, quando observados, constituem importante medida preventiva nessa seara, contribuindo para evitar, entre outras consequências nocivas, o alarmante número de casos de acidente de trabalho e distúrbios biológicos. Nesse sentido, Alice Monteiro de Barros expõe que

a finalidade dos intervalos intra e interjornada é proporcionar ao trabalhador a oportunidade de alimentar-se, descansar e repor suas energias. Sua manutenção é indispensável, na medida em que o trabalho realizado em jornadas prolongadas contribui para a fadiga física e psíquica, conduzindo à insegurança no meio ambiente de trabalho (2009, p. 682).

A natureza jurídica do intervalo intrajornada é de direito do empregado (CASSAR, 2013, p. 715). O tempo padrão de duração desse direito está regulado no artigo 71 da CLT, com destaque para o caput e os parágrafos $1^{\circ}$ e $3^{\circ}$, a seguir transcritos:

Art. 71 - Em qualquer trabalho contínuo, cuja duração exceda de 6 (seis) horas, é obrigatória a concessão de um intervalo para repouso ou alimentação, o qual será, no mínimo, de 1 (uma) hora e, salvo acordo escrito ou contrato coletivo em contrário, não poderá exceder de 2 (duas) horas.

$\S 1^{\circ}$ - Não excedendo de 6 (seis) horas o trabalho, será, entretanto, obrigatório um intervalo de 15 (quinze) minutos quando a duração ultrapassar 4 (quatro) horas.

(...)

$\S 3^{\circ} \mathrm{O}$ limite mínimo de uma hora para repouso ou refeição poderá ser reduzido por ato do Ministro do Trabalho, Indústria e Comércio, quando ouvido o Serviço de Alimentação de Previdência Social, se verificar que o estabelecimento atende integralmente às exigências concernentes à organização dos refeitórios, e quando os respectivos empregados não estiverem sob regime de trabalho prorrogado a horas suplementares.

Rev. de Direito do Trabalho e Meio Ambiente do Trabalho | e-ISSN: 2525-9857 | Porto Alegre | v. 4 | n. 2 | p. 135 - 155 |

Jul/Dez. 2018 


\section{ALTERAÇÃO DA DURAÇÃO DO INTERVALO INTRAJORNADA NA REFORMA TRABALHISTA À LUZ DOS PRINCÍPIOS DA VEDAÇÃO DO RETROCESSO SOCIAL E DA PROGRESSIVIDADE DA CONDIÇÃO SOCIAL DOS TRABALHADORES}

A regra geral é a de que o intervalo do empregado urbano com jornada acima de seis horas tem duração de uma a duas horas. No caso de jornada acima de quatro e até seis horas, fixou-se a obrigatoriedade de intervalo de quinze minutos.

Como se observa, a legislação trabalhista, ao destinar tempos diferenciados para "repouso ou alimentação", a depender da extensão da jornada, reconhece a necessidade de recuperação física e mental e de nutrição do trabalhador.

Cumprindo sua característica finalidade protetiva, a normativa trabalhista estabelece, principalmente, os limites mínimos intervalares. Não havia na CLT, antes da reforma, qualquer previsão de negociação para a redução intervalar, diferentemente do que ocorria na situação de elastecimento, permitida caso firmado "acordo escrito ou contrato coletivo" (artigo 71, caput, da CLT).

A única hipótese de redução era a prevista no parágrafo $3^{\circ}$, ainda vigente, que, exclusivamente em relação ao empregado sujeito a jornada superior a seis horas, permite a diminuição do tempo intervalar de uma hora por meio de decisão administrativa do Ministério do Trabalho, desde que atendidas às exigências relativas à organização dos refeitórios e a não submissão dos empregados a regime de prorrogação da jornada de trabalho. Essas exigências revelam de forma clara a natureza profilática e biológica do intervalo, pois a mencionada norma só admite a redução se for evitado o desgaste decorrente da prorrogação de jornada e se for constatado pelo Ministério do Trabalho que no tempo menor que o mínimo legal os empregados terão acesso adequado à alimentação.

Tendo em vista a finalidade a que se propõem, as disposições da CLT relacionadas à duração do direito ao intervalo intrajornada, acima mencionadas, contidas no texto original da CLT, densificam o direito fundamental social de "redução dos riscos inerentes ao trabalho, por meio de normas de saúde, higiene e segurança" estabelecido no artigo $7^{\circ}$, XXII, da Constituição Federal. Revestem-se, portanto, de fundamentalidade.

Consonantemente, o Tribunal Superior do Trabalho construiu jurisprudência reconhecedora do intervalo intrajornada como "norma de saúde, higiene e segurança". Não sem razão, firmou o entendimento de não ser possível negociação coletiva com o objetivo de suprimir ou reduzir o tempo destinado ao intervalo intrajornada. É o que se constata de sua Súmula 437, II: 


\begin{abstract}
(...)
II - É inválida cláusula de acordo ou convenção coletiva de trabalho contemplando a supressão ou redução do intervalo intrajornada porque este constitui medida de higiene, saúde e segurança do trabalho, garantido por norma de ordem pública (art. 71 da CLT e art. $7^{\circ}$, XXII, da CF/1988), infenso à negociação coletiva.
\end{abstract}

Trata-se de entendimento consolidado há mais de uma década, tendo a redação da súmula sido, anteriormente, fixada na OJ 342 da SBDI-1 do TST (DJ 22/06/2004).

Pode-se concluir, assim, que o entendimento de que o direito ao intervalo intrajornada constitui medida de higiene, saúde e segurança do trabalho, amplamente adotado pela jurisprudência trabalhista, formou "consenso geral", nos termos da teoria sobre a vedação do retrocesso exposta no tópico anterior, vinculando o legislador, portanto, ao núcleo essencial do direito fundamental concretizado.

A reforma trabalhista efetuou alterações normativas que impactaram o tema da duração do intervalo intrajornada e que merecem discussão quanto à sua validade.

Com a inclusão do artigo 611-A na CLT pela Lei 13.467/2017, passou-se a prever hipóteses em que a negociação coletiva tem prevalência sobre a lei. Dentre essas hipóteses, insere-se, no inciso III a possibilidade de redução da duração do intervalo intrajornada para trinta minutos nos casos de jornada superiores a seis horas:

Art. 611-A. A convenção coletiva e o acordo coletivo de trabalho têm prevalência sobre a lei quando, entre outros, dispuserem sobre:

(...)

III - intervalo intrajornada, respeitado o limite mínimo de trinta minutos para jornadas superiores a seis horas;

Apesar de no artigo 611-B, XVII, da CLT, igualmente incluído pela reforma, considerar-se a supressão ou redução de "normas de saúde, higiene e segurança do trabalho previstas em lei ou em normas regulamentadoras do Ministério do Trabalho" como objeto ilícito da negociação coletiva, previsão desnecessária em face da proteção já conferida no artigo $7^{\circ}$, XXII, da Constituição Federal, o parágrafo único do mesmo artigo da CLT estabeleceu que as regras sobre duração do trabalho e intervalos não são consideradas como normas de saúde, higiene e segurança para fins de afastar supressão ou redução de direitos por meio de negociação coletiva:

Art. 611-B. Constituem objeto ilícito de convenção coletiva ou de acordo coletivo de trabalho, exclusivamente, a supressão ou a redução dos seguintes direitos:

(...)

XVII - normas de saúde, higiene e segurança do trabalho previstas em lei ou em normas regulamentadoras do Ministério do Trabalho;

(...)

Rev. de Direito do Trabalho e Meio Ambiente do Trabalho | e-ISSN: 2525-9857 | Porto Alegre | v. 4 | n. 2 | p. 135 - 155 |

Jul/Dez. 2018 


\section{ALTERAÇÃO DA DURAÇÃO DO INTERVALO INTRAJORNADA NA REFORMA TRABALHISTA À LUZ DOS PRINCÍPIOS DA VEDAÇÃO DO RETROCESSO SOCIAL E DA PROGRESSIVIDADE DA \\ CONDIÇÃO SOCIAL DOS TRABALHADORES}

Parágrafo único. Regras sobre duração do trabalho e intervalos não são consideradas como normas de saúde, higiene e segurança do trabalho para os fins do disposto neste artigo.

O parágrafo único do artigo 611-B da CLT, ao dispor que as regras sobre duração do trabalho e intervalos não são consideradas como normas de saúde, higiene e segurança do trabalho para fins como o de redução do tempo de intervalo intrajornada para jornadas superiores a seis horas, conforme previsto no art. 611-A, da CLT, visa elidir a incidência de direito fundamental e contrariar reconhecimento fático consolidado na jurisprudência trabalhista. Constitui tentativa de, por meio de lei, desconsiderar a lógica, criando situação fática artificial. A lei não pode, todavia, alterar a natureza das coisas, de forma a burlar normas de hierarquia superior e torná-las inócuas. Tal alternativa é uma forma simplória de o legislador ordinário afastar o enquadramento silogístico de preceitos idealizados por normas de direitos fundamentais.

Dessa forma, conclui-se que o artigo 611-B, parágrafo único, da CLT é, nesse ponto, inconstitucional.

E em relação ao artigo 611-A, III, do mesmo diploma?

A previsão de prevalência da negociação coletiva sobre a lei em matéria trabalhista é um assunto que gerará, de forma ampla, diversos questionamentos quanto aos seus limites, tendo em vista a concentração, nesta seara, de normas de natureza de ordem pública, garantidoras de condições mínimas de proteção ao trabalho.

Incialmente, é importante ressaltar que a negociação coletiva se orienta pelo princípio da progressividade dos direitos sociais. $\mathrm{O}$ "reconhecimento das convenções e acordos coletivos de trabalho", previsto no artigo $7^{\circ}, \mathrm{XXVI}$, da Constituição Federal, está vinculado ao caput do mesmo artigo constitucional, que, ao instituir rol de direitos trabalhistas, visou a melhoria da condição social dos trabalhadores urbanos e rurais: "Art. $7^{\circ}$ São direitos dos trabalhadores urbanos e rurais, além de outros que visem à melhoria de sua condição social". Como direito social, a negociação coletiva deve ser exercida em conformidade com seu legado histórico de conquista e de instrumento de promoção de melhores condições de trabalho.

A progressividade dos direitos sociais dos trabalhadores, intimamente relacionada ao princípio da vedação do retrocesso, analisado no tópico anterior deste artigo, não permite que a negociação coletiva reduza o patamar das condições sociais já alcançadas.

Quanto à relação entre o negociado e o legislado, é de se destacar a formulação de Maurício Godinho Delgado a respeito do que denomina de “princípio da adequação setorial 
negociada". Por esse princípio, as normas negociadas podem prevalecer sobre as disposições heterônomas se observarem dois critérios. O primeiro se satisfaz "quando as normas autônomas juscoletivas implementam um padrão setorial de direitos superior ao padrão geral oriundo da legislação heterônoma aplicável" (2008, p. 1545-1546), respeitando-se, assim, o princípio da progressividade. O segundo é preenchido "quando as normas autônomas juscoletivas transacionam setorialmente parcelas justrabalhistas de indisponibilidade apenas relativa (e não de indisponibilidade absoluta)" (2008, p. 1545-1546).

Embora no processo de identificação das normas trabalhistas de indisponibilidade absoluta, portadoras de especial interesse público, possa-se falar em certa zona cinzenta, a dúvida não permanece nas situações em que estão em análise direitos fundamentais, como nos casos das normas relativas à proteção de saúde, segurança e higiene no trabalho. Essas estariam incluídas, na terminologia do citado jurista, em um

\footnotetext{
patamar civilizatório mínimo que a sociedade democrática não concebe ver reduzido em qualquer segmento econômico-profissional, sob pena de se afrontarem a própria dignidade da pessoa humana e a valorização pertinente ao trabalho (arts. $1^{\circ}$, III e 170, caput, CF/88)" (2012, p. 1417).
}

Essa é a hipótese do intervalo intrajornada, direito que, por concretizar direito fundamental social, está, em face de sua natureza, ligado à dignidade do trabalhador.

A indisponibilidade do direito ao intervalo intrajornada está vinculada, contudo, às finalidades protetivas do próprio direito intervalar e do direito fundamental que densifica. Querse dizer, com isso, que a indisponibilidade desse direito somente se verifica na parcela necessária ao desempenho de seu papel jurídico. Ou seja, a norma coletiva poderia interferir no lapso temporal intervalar até o ponto em que não prejudicasse sua finalidade protetiva.

A lei estabelece, no artigo 71 da CLT, um lapso temporal mínimo de duração do intervalo padronizado a todos os trabalhadores. Cria presunção de que o tempo mínimo delimitado é o necessário à recuperação física e mental e à nutrição do trabalhador. Ao assim proceder, visa preservar a saúde e segurança do empregado. Essa finalidade, não o tempo presumido estabelecido, é o núcleo essencial - coincidente e concretizador da proteção do direito fundamental social do artigo $7^{\circ}$, XXII, da Constituição Federal - que não pode ser violado. Aceitando-se essa premissa, tem-se, consequentemente, que lei posterior pode permitir a modulação, por meio de negociação coletiva, do limite temporal mínimo, de acordo com a realidade de trabalho, se respeitar o núcleo essencial do direito ao intervalo intrajornada. 


\section{ALTERAÇÃO DA DURAÇÃO DO INTERVALO INTRAJORNADA NA REFORMA TRABALHISTA À LUZ DOS PRINCÍPIOS DA VEDAÇÃO DO RETROCESSO SOCIAL E DA PROGRESSIVIDADE DA CONDIÇÃO SOCIAL DOS TRABALHADORES}

É de conhecimento de todos que existem vários tipos e formas de trabalho, cada qual com características e exigências próprias. Nos trabalhos braçais, a exemplo de pedreiros e serventes na construção civil, sobressai o esforço físico. Nos trabalhos intelectuais, por outro lado, como no caso de arquitetos, há maior desgaste mental. Há atividades que exigem atenção constante, como, por exemplo, nas de manuseio de máquinas e ferramentas perigosas e de direção de veículos automotores. Em outras, por outro lado, a concentração necessária ao desempenho das atividades não é requerida no mesmo nível, a exemplo do trabalho de portaria de edifícios residenciais. Em trabalhos de grande esforço físico, além do elevado tempo de descanso para recuperação do desgaste, também se verifica necessidade de mais tempo para alimentação e, principalmente, digestão, diferentemente do que ocorre com trabalhos sedentários. Considerando a diversidade do mundo do trabalho, razoável concluir que o tempo necessário para descanso e recuperação antes de retornar ao trabalho pode variar entre as atividades. A redução do tempo intervalar abaixo do padrão mínimo legal depende, portanto, de se constatar que o tempo estabelecido em instrumento coletivo permita que o trabalho seja executado de forma segura e saudável, constituindo-se requisito a ser observado pela negociação coletiva. Os meios e critérios para a verificação da duração do intervalo intrajornada necessária para o desempenho do labor de forma segura e saudável merecem desenvolvimento de discussão mais profunda, que fogem ao escopo do presente trabalho. Entretanto, encontramos na própria lei pelo menos três hipóteses que, se não observadas cumulativamente, frustram o requisito.

A primeira hipótese é a de inexistência de prorrogação da jornada. Trata-se de densificação do direito fundamental social do artigo $7^{\circ}$, XXII, da Constituição Federal promovida pelo parágrafo $3^{\circ}$ do artigo 71 da CLT que não pode, em razão do princípio da vedação do retrocesso, ser afastada por negociação coletiva. A norma visa proteger o empregado que trabalha para além da jornada normal e que, consequentemente, está sujeito a desgaste em proporção cada vez maior à medida que o tempo de trabalho se acumula.

A segunda hipótese é a de ser possível ao empregado se alimentar adequadamente. Baseia-se na mesma densificação realizada pelo dispositivo da CLT citado na hipótese precedente, gerando igual efeito. Assim, ainda que seja estabelecida redução do tempo de intervalo em norma coletiva, torna-se necessário verificar se o estabelecimento atende integralmente às exigências concernentes à organização dos refeitórios, nos termos da 
regulamentação do Ministério do Trabalho, ou que existam serviços de alimentação de fácil e rápido acesso no entorno do estabelecimento em que o empregado desempenha suas atividades.

A terceira hipótese é a observância da duração mínima de trinta minutos para a jornada com mais de seis horas, nos termos do inciso III do artigo 611-A na CLT. O legislador reformista considerou que, na situação regulada, não há modalidade de trabalho que dispense a observância de pelo menos trinta minutos de descanso. Repita-se, contudo, que, nesta hipótese, qualquer lapso temporal intervalar inferior a uma hora até este novo limite mínimo de trinta minutos estabelecido em lei somente é aplicável se ficar constatado que não haverá prejuízo à segurança e saúde do trabalhador no desempenho das suas atividades.

Uma vez preservados os preceitos de ordem pública, por meio de promoção de saúde e segurança no trabalho, impõe-se como requisito, igualmente, a realização de negociação coletiva em benefício dos empregados, de forma a se implementar o princípio da progressividade da condição social dos trabalhadores (artigo $7^{\circ}$, caput, da $\mathrm{CF}$ ).

Refletindo a negociação coletiva a real expressão do interesse da categoria profissional, entendemos que é possível ser considerada benéfica redução intervalar por meio de negociação coletiva. Não sendo o intervalo intrajornada computado na duração do trabalho (artigo 71, § 2, da CLT), sua redução, no caso de inexistência de prorrogação de jornada, permitiria o retorno ao lar mais cedo. Como resultado, o descanso interjornada seria ampliado, permitindo-se a substituição de eventual tempo ocioso por melhor proveito de outros valores constitucionalmente tutelados. Preservado, portanto, o núcleo essencial do direito fundamental do artigo $7^{\circ}$, XXII, da Constituição Federal, oportuniza-se a promoção de outros direitos. O empregado poderia, assim, exemplificativamente: desfrutar de mais tempo com a família (artigo 226 da CF); reservar mais tempo para a prática esportiva (artigo 217 da CF), intimamente ligada ao próprio direito à saúde (artigo $6^{\circ} \mathrm{da} \mathrm{CF}$ ), defendido anteriormente aqui na esfera do trabalho; e acrescer tempo dedicado ao lazer (artigo $6^{\circ}$ da $\mathrm{CF}$ ) ou a atividades culturais (artigo 215 da $\mathrm{CF})$.

Diante do exposto, entendemos que, utilizando-se interpretação conforme a constituição, é possível atribuir validade ao artigo 611-A, III, da CLT, incluído pela Lei 13.467, de 13 de julho de 2017. 


\section{ALTERAÇÃO DA DURAÇÃO DO INTERVALO INTRAJORNADA NA REFORMA TRABALHISTA À LUZ DOS PRINCÍPIOS DA VEDAÇÃO DO RETROCESSO SOCIAL E DA PROGRESSIVIDADE DA \\ CONDIÇÃO SOCIAL DOS TRABALHADORES}

CONCLUSÃO

Tendo em vista os princípios da vedação do retrocesso e da progressividade da condição social dos trabalhadores e as disposições contidas no texto original da CLT relacionadas à duração do direito ao intervalo intrajornada (artigo 71, caput e parágrafos $1^{\circ} \mathrm{e}$ $3^{\circ}$ ), densificadoras do direito fundamental social de "redução dos riscos inerentes ao trabalho, por meio de normas de saúde, higiene e segurança", situada no artigo $7^{\circ}$, XXII, da Constituição Federal, somente será admissível a redução do tempo destinado ao intervalo intrajornada por meio de norma coletiva se constatada a inexistência de prejuízo a saúde e segurança do empregados atingidos e se negociação coletiva for realizada em benefício dos empregados, nos termos do exposto no desenvolvimento do artigo.

Num contexto de globalização econômica e neoliberalismo, marcado pelo sobrepujamento de interesses mercadológicos, o constitucionalismo e os direitos fundamentais levantam-se como uma esperança de controle e propagação do pensamento de uma ordem jurídica voltada para servir ao ser humano. Nas palavras de Jorge Reis Novais "um trunfo contra a maioria", mesmo quando esta atua de acordo com os procedimentos democráticos instituídos ${ }^{8}$. Trunfo esse reconhecido "como exigência material do reconhecimento da dignidade da pessoa humana" e "como consequência da consagração constitucional da indisponibilidade dos direitos fundamentais e da correspondente vinculação das entidades públicas"9.

\section{REFERÊNCIAS BIBLIOGRÁFICAS}

ALEXY, Robert. Teoria dos direitos fundamentais. Tradução de Virgílio Afonso da Silva. 2. ed. 3. tir. São Paulo: Malheiros, 2014.

BARBOSA, Estefânia Maria de Queiroz. Precedentes judiciais e segurança jurídica: fundamentos e possibilidades para a jurisdição constitucional brasileira. São Paulo: Saraiva, 2014.

BARROS, Alice Monteiro. Curso de Direito do Trabalho. 5. ed. rev e ampl. São Paulo: LTr, 2009.

BARROSO, Luís Roberto. O direito constitucional e a efetividade de suas normas: limites e possibilidade da Constituição brasileira. 6. ed. atual. Rio de Janeiro: Renovar, 2002.

BARROSO, Luís Roberto; BARCELlOS, Ana Paula de. O começo da história. A nova interpretação constitucional e o papel dos princípios no direito brasileiro. Revista de Direito

\footnotetext{
${ }^{8}$ NOVAIS, Jorge Reis. Direitos Fundamentais: Trunfos contra a maioria. Coimbra: Coimbra Editora, 2006. p. 18

${ }^{9}$ Ibidem. ps. 27-28.
} 
Administrativo, v. 232, Rio de Janeiro: FVG, 2003. Disponível em: <http://bibliotecadigital.fgv.br/ojs/index.php/rda/article/view/45690> Acesso em 20 ago. 2017.

BRASIL, Constituição Federal de 1988.

BRASIL, Consolidação das Leis do Trabalho. Decreto-lei n n 5.452, de 1 de maio de 1943.

BRASIL, Decreto no 591, de 6 de julho de 1992.

CASSAR, Vólia Bomfim. Direito do Trabalho. $8^{\circ}$. ed. rev. e atual. Rio de Janeiro: Forense; São Paulo: Método, 2013. p. 715.

COUTINHO, Aldacy Rachid. A dimensão do princípio da dignidade e a relação de trabalho. In: SARLET, Ingo Wolfgang; MELLO FILHO, Luiz Philippe Vieira de; FRAZÃO, Ana de Oliveira. (Coord.). Diálogos entre o Direito do Trabalho e o Direito Constitucional: estudos em homenagem a Rosa Maria Weber. São Paulo: Saraiva, 2014.

DELGADO, Maurício Godinho. Curso de Direito do Trabalho. 7. ed. São Paulo: LTr, 2008.

DELGADO, Maurício Godinho. Curso de Direito do Trabalho. 11. ed. São Paulo: LTr, 2012.

DERBLI, Felipe. A aplicabilidade do princípio da proibição do retrocesso social no direito brasileiro. In: SOUZA NETO, Cláudio Pereira; SARMENTO, Daniel; (Coord.). Direitos sociais. Fundamentos, judicialização e direitos sociais em espécie. Rio de Janeiro: Lumen Juris, 2008.

DERBLI, Felipe. O princípio da proibição do retrocesso social na Constituição de 1988. Rio de Janeiro: Renovar, 2007.

DUQUE, Marcelo Schenk. Curso de Direitos Fundamentais: Teoria e Prática. São Paulo: Editora Revista dos Tribunais, 2014.

GARCÍA, Pedro de Veja. Mundialización y Derecho Constitucional: la crisis del principio democrático en el constitucionalismo actual. Revista de Estudios Políticos (Nueva Época), n. 100, Abril-Junio 1998, p. 13. Disponível em: <file:///C:/Users/dirit/Downloads/DialnetMundializacionYDerechoConstitucional-27492.pdf> Acesso em 06 ago. 2017.

HACHEM, Daniel Wunder. Mínimo existencial e direitos fundamentais econômicos e sociais: distinções e pontos de contato à luz da doutrina e jurisprudência brasileiras. In: BACELLAR FILHO, Romeu Felipe; HACHEM, Daniel Wunder (Coord.). Direito público no Mercosul: intervenção estatal, direitos fundamentais e sustentabilidade. Belo Horizonte: Fórum, 2013.

HESSE, Konrad. A força normativa da Constituição. Porto Alegre: Sergio Antonio Fabris Editor, 1991.

LIMA, Abili Lázaro Castro de. A globalização econômica e a dissipação dos direitos sociais. A\&C Revista de Direito Administrativo e Constitucional, Belo Horizonte, ano 6, n. 26, p. 37-58, out./dez. 2006.

NOVAIS, Jorge Reis. As restrições aos direitos fundamentais não expressamente autorizadas pela constituição. Coimbra: Coimbra Editora, 2003.

NOVAIS, Jorge Reis. Direitos fundamentais: Trunfos contra a maioria. Coimbra: Coimbra Editora, 2006.

NOVAIS, Jorge Reis. Direitos sociais: teoria jurídica dos direitos sociais enquanto direitos fundamentais. 1. ed. Coimbra: Coimbra Editora, 2010. 
NUNES, António José Avelãs. Os trabalhadores e a crise do capitalismo. 1. ed. Florianópolis: Empório do Direito, 2016.

OXFAM, Relatório completo de 2017 "uma economia para os 99\%”. Disponível em: <https://www.oxfam.org.br/publicacoes/uma-economia-para-os-99> Acesso em 12 ago. 2017

ROMITA, Arion Sayão. Direitos fundamentais nas relações de trabalho. 5. ed. ver. e aumentada. São Paulo: LTr, 2014.

SALA, Agustí. La desigualdade social aumenta em España a pesar del crecimiento. El Periódico de Aragón, 16 jan. 2017.2 Disponível em: <http://www.elperiodicodearagon.com/noticias/economia/desigualdad-social-aumentaespana-pesar-crecimiento_1173532.html>. Acesso em 19 ago. 2017.

SARLET, Ingo Wolfgang. A eficácia do direito fundamental à segurança jurídica: dignidade da pessoa humana, direitos fundamentais e proibição de retrocesso social no direito constitucional brasileiro. [2005]. Disponível em: <http://www.tex.pro.br/images/stories/PDF_artigos/aeficacia_ingo_wlfgang_sarlett.pdf> Acesso em 26 ago. 2017

SARLET, Ingo Wolfgang. A eficácia dos direitos fundamentais: uma teoria geral dos direitos fundamentais na perspectiva constitucional. 12. ed. rev. atual e ampl. Porto Alegre: Livraria do Advogado Editora, 2015.

SARLET, Ingo Wolfgang; MARINONI, Luiz Guilherme; MITIDIERO, Daniel. Curso de direito constitucional. 2. ed. atual. e ampl. São Paulo: Editora Revista dos Tribunais, 2013.

SARMENTO, Daniel. Direitos sociais e globalização: limites ético-jurídicos ao realinhamento constitucional. Revista de Direito Administrativo, v. 223, Rio de Janeiro: FVG, 2001.

SCHIER, Paulo Ricardo; SCHIER, Adriana da Costa Ricardo. Serviço público adequado e a cláusula de proibição de retrocesso social. Revista de Direito da Administração Pública, Niterói, ano 2, vol. 1, n¹, 2016.

SCHIER, Paulo Ricardo. Novos desafios da filtragem constitucional no momento do neoconstitucionalismo. A\&C Revista de Direito Administrativo e Constitucional, Belo Horizonte, ano 5, n. 20, abr./jun. 2005.

TEJADA, Javier Tajadura. La crisis de los derechos sociales en el contexto de la mundialización. In: Nuevas Políticas Públicas: Anuario multidisciplinar para la modernización de las Administraciones Públicas, año 2006, n.2, ps. 120-137. Disponível em: <https://dialnet.unirioja.es/revista/7332/A/2006> Acesso em 06 ago. de 2017. 